\title{
Treatment for morbid obesity
}

\author{
A R Carmichael
}

\section{Summary}

There is no single unifying theory to explain the aetiology of obesity but several environmental factors, such as decreased physical activity and increased fat intake may contribute to its development in genetically predisposed individuals. Dietary and pharmacological treatments of morbid obesity have been proven to be unsuccessful. Modern surgical treatments have been shown to be effective in achieving significant weight loss with consequent reduction in morbidity. Despite the fact that surgical treatment of morbid obesity is the only therapeutic form that has stood the test of time, it still remains a crisisdriven form of therapy in the UK. It is probable that a better understanding of the aetiology and physiology of obesity may lead to the development of an effective pharmacological treatment of obesity in the future. However, until then, surgical treatment of morbid obesity should be considered as an effective and efficient way of treatment in selected cases.

Keywords: obesity

Table 1 Weight classification based on BMI (adapted from WHO Technical Report Series no 854)

\begin{tabular}{lll}
\hline & BMI & Description \\
\hline Ungraded & $<20$ & underweight \\
Grade 0 & $20-24.9$ & desirable weight \\
Grade 1 & $25-29.9$ & overweight \\
Grade 2 & $30-40$ & obese \\
Grade 3 & $>40$ & morbidly obese \\
\hline
\end{tabular}

19 Water Meadows, Fordwich, Canterbury, CT2 0BF, UK A R Carmichael

Accepted 4 August 1998
Obesity is an increasing health problem. Obesity is not only recognised as a disease in its own right, but is also a major risk factor for common diseases such as ischaemic heart disease, hypertension, non-insulin dependent diabetes mellitus (NIDDM), cholelithiasis, and certain cancers. It is therefore not surprising that obesity reduces longevity. ${ }^{1}$

\section{Definitions}

A commonly used surrogate assessment of obesity is the body mass index (BMI) which is weight in kilograms divided by height in metres squared. This was first described by Quetelet in $1869 .^{2}$ In a young adult, the desirable range of BMI is $20-25 \mathrm{~kg} / \mathrm{m}^{2}$, as this is associated with the lowest mortality. A summary of weight classification based on BMI, graded to indicate the degree of risk to health, is given in table 1 . These grades of obesity should not be used rigidly since body frame and build have to be considered. Though useful at a population level, BMI has its limitations, for example, in a young muscular body builder and a middleaged obese woman BMI may be identical though the former may not be obese and the health implications are very different. Other markers of obesity include waist circumference and waist:hip ratio which have been shown to predict adverse risk. Thus, a waist circumference greater than $102 \mathrm{~cm}$ and $87 \mathrm{~cm}$ in men and women, respectively, indicates adverse risk. ${ }^{3}$

\section{Historical background}

Obesity was first recorded as a medical disorder by the ancient Greeks, when Hippocrates observed that very fat individuals were more liable to sudden death than thin individuals. Other great medical scholars through the ages have also drawn attention to the adverse effects of obesity. Thus, Avicenna in his famous Cannon of medicine (circa 11th century) perceptively described the hazards of obesity as narrowed blood vessels, obstructed breathing, stroke, infertility, weak libido, and sudden death. Attitudes to obesity have varied throughout history. In medieval times, obesity was regarded as a sign of affluence being the prerogative of Barons, Lords and the Clergy. ${ }^{4}$ In the renaissance period, the paintings and sculptures of well-padded females by Botticelli, Da Vinci and Raphael or the curvaceous nudes of Rubens all suggest that a certain degree of obesity was admired. In the 18th century, the possession of a bulging paunch was not regarded as exceptional or as a matter of shame. ${ }^{5}$ By the late 19 th century, there were signs of a shift in attitude with obesity being regarded as an affliction. ${ }^{6}$ Thinness was now regarded as a symbol of feminine beauty and in upper class society, there was interest in slimming aids such as ephedrine. Such attitudes have continued into the 20th century and have been reinforced by the re-discovery of related health risks. Nevertheless, it is only in recent years that the problem of obesity has been considered worthy of scientific and medical study. Thus, a better understanding of predisposing factors, underlying mechanisms and metabolic consequences, has enabled better insight to the treatment of obesity.

\section{Epidemiology}

In developed countries, obesity is an increasingly common condition. In Europe, it has been estimated that $10-20 \%$ of all men and $15-25 \%$ of women are obese. ${ }^{7}$ The prevalence of obesity has more than doubled in the UK between 1980 and 1993 and this trend has been uniform for both men and women of all age groups (see figure 1). The North American experience has been the same. ${ }^{7}$

The underlying mechanism for this increase is unclear, although a number of possibilities have been postulated. Due to the rate of increase, a genetic basis is unlikely. It is a reasonable assumption that environmental factors are the main reason. Evidence in support of this include a 50\% increase in the consumption of fat since 1940 in the UK, ${ }^{8}$ nevertheless over the period in question there has been a $20 \%$ reduction in per capita consumption of calories. A likely explanation 


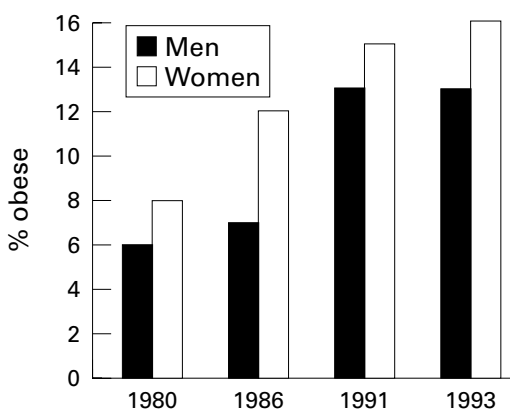

Figure 1 Incidence of obesity in men and women aged between 16 and 64 years in the UK (data taken from Office of Population Consensus and Surveys)

\begin{tabular}{|c|}
\hline $\begin{array}{l}\text { Morbidity associated with } \\
\text { obesity }\end{array}$ \\
\hline $\begin{array}{l}\text { Cardiovascular } \\
\text { - coronary heart disease } \\
\text { - hypertension } \\
\text { - stroke } \\
\text { - deep venous veins } \\
\text { - sudden death }\end{array}$ \\
\hline $\begin{array}{l}\text { Osteoarthritis } \\
\text { - spine } \\
\text { - hip } \\
\text { - knee }\end{array}$ \\
\hline $\begin{array}{l}\text { Metabolic } \\
\text { - dyslipidaemia } \\
\text { - impaired glucose tolerance } \\
\text { - non-insulin dependent diabetes } \\
\text { mellitus } \\
\text { - insulin resistance } \\
\text { gout } \\
\text { polycystic ovary syndrome }\end{array}$ \\
\hline $\begin{array}{l}\text { Respiratory tract } \\
\text { - dyspnoea } \\
\text { - sleep apnoea }\end{array}$ \\
\hline $\begin{array}{l}\text { Cancer } \\
\text { - in men: colorectal, prostate } \\
\text { - in women: breast, uterus, ovary, } \\
\text { gallbladder }\end{array}$ \\
\hline $\begin{array}{l}\text { Nervous system } \\
\text { - depression } \\
\text { - low self-esteem } \\
\text { - suicide attempt }\end{array}$ \\
\hline $\begin{array}{l}\text { Digestive tract } \\
\text { - hiatus hernia } \\
\text { - gall stones } \\
\text { - fatty liver } \\
\text { - herniae }\end{array}$ \\
\hline $\begin{array}{l}\text { Urological } \\
\text { - proteinuria } \\
\text { stress incontinence }\end{array}$ \\
\hline $\begin{array}{l}\text { Skin } \\
\text { - fungal infection } \\
\text { - sweat rashes } \\
\text { - cellulitis } \\
\text { acanthosis nigrans }\end{array}$ \\
\hline $\begin{array}{l}\text { Obstetrics } \\
\text { - infertility } \\
\text { - large babies } \\
\text { - neural tube defects }\end{array}$ \\
\hline
\end{tabular}

Box 1 for the increase in obesity despite decreasing food intake, is the decline in physical activity that has accompanied increasing affluence and changes in work practice. ${ }^{9}$ This increasing incidence of obesity is a major health concern, since it is an important risk factor for numerous life-threatening and debilitating diseases. The Health of the Nation initiative has recognised obesity as a key target. The aim is to reduce the number of obese adults to $7 \%$ or less by the year 2000 .

\section{Aetiology}

To date, there is no single unifying theory to explain the aetiology of obesity. An important, though simple, concept of obesity is that it results from an imbalance between energy intake and energy expenditure. A net positive energy balance associated with obesity is multifactorial in origin as genetic, environmental and psychosocial factors may all have a contributory role.

GENETIC/ENDOCRINE FACTORS

It is well recognised that certain genetically determined syndromes have obesity as an important part of their phenotype, for example, the Prader-Willi and the Bardet-Biedel syndromes. Endocrinological abnormalities may also predispose individuals to obesity, such as hypothyroidism, Cushing's syndrome and the Stein-Leventhal syndrome.

BASAL METABOLIC RATE

The basal or resting metabolic rate (BMR) is the energy expenditure of an individual at rest, following an overnight fast and at a comfortable environmental temperature in a thermoneutral range. Paradoxically, several studies have shown that obese individuals have a higher BMR compared to their lean counterparts. ${ }^{9}$ The increase in BMR is thought to be mainly due to an increase in fat-free mass which increases pari passu with fat mass. Other studies have suggested that infants, children and Pima Indians who all have a low BMR are predisposed to obesity. These findings have not been confirmed in longitudinal studies. ${ }^{10}$

\section{PHYSICAL ACTIVITY}

Physical activity may represent $20-50 \%$ of total energy expenditure of a given individual. Total energy expenditure over a 10-20 day period can be accurately performed by using a double-labelled water method. ${ }^{9}$ The ratio of total energy expenditure to BMR gives a physical activity level index which is markedly reduced in people with a BMI of more than $35 \mathrm{~kg} / \mathrm{m}^{2}$. The limitation of this index is that it has no predictive value, thus the reduced value in individuals with a high BMI probably reflects reduced physical activity as a consequence of the increased BMI. ${ }^{9}$

\section{SUBSTRATE OXIDATION}

In energy-balanced individuals, the oxidised fuel must match that of the consumed fuel. Changes in the composition of an individual's diet can have a profound influence on substrate oxidation in the absence of any change in total energy expenditure. ${ }^{11}$ It is hypothesised that obese individuals are unable to increase fat oxidation to match dietary fat intake. ${ }^{12}$ Overall, there is little evidence to support the hypothesis that human obesity is due to specific defects in energy expenditure in predisposed individuals.

\section{Health consequences of obesity}

Obesity contributes to mortality from the three largest causes in the UK, namely, cardiovascular, cancer and respiratory disease. There is increasing evidence for an association between excessive body weight and mortality. In North America the Nurses' Health Study, which analysed 115195 women, demonstrated that $53 \%$ of all deaths among women with a BMI $>29$ could be attributed directly to obesity. An increased risk of mortality was demonstrated for greater degrees of obesity with a relative risk (RR) of $1.3,1.6$, and 2.1 in those with a BMI of 25.026.9, 27.0-28.9, and 29.0-31.9, respectively. ${ }^{1}$ In women with a BMI>32 who have never smoked, the risk of death was 4.1 and 2.1 from cardiovascular disease and cancer, respectively. Other studies have confirmed these findings. ${ }^{13}$ As for other risk factors, weight reduction has been demonstrated to reduce risk. Thus, a weight loss of more than $9 \mathrm{~kg}$ in women has been associated with a $25 \%$ decrease in all-cause mortality. ${ }^{14}$ Diseases associated with obesity are listed in box 1 .

CARDIOVASCULAR DISEASE

The Framingham Heart Study demonstrated that weight gain after the young adult years carried an increased risk of coronary heart disease (CHD) in both 
Table 2 American Cancer Society study: mortality ratio $(n=750000 ; 12$-year follow-up)

\begin{tabular}{lll}
\hline & \multicolumn{2}{l}{ Mortality ratio } \\
\cline { 2 - 3 } & $\begin{array}{l}\text { 120-129\% } \\
\text { ideal body } \\
\text { weight }\end{array}$ & $\begin{array}{l}>140 \% \\
\text { ideal body } \\
\text { weight }\end{array}$ \\
\hline Site & & \\
\hline Men & & 1.73 \\
$\quad$ Colorectal & 1.37 & 1.29 \\
$\quad$ Prostate & & 5.42 \\
Women & 1.85 & 2.39 \\
Endometrium & 1.51 & 1.63 \\
$\quad$ Cervix & & 1.63 \\
$\quad$ Ovary & & \\
Breast & & \\
\hline
\end{tabular}

From Deslypere JP. Obesity and cancer. Metabolism 1995;449(suppl 3):24-7. sexes. This increased risk could neither be attributed to the initial weight nor to the accrued risk factors resulting from the weight gain. ${ }^{15}$ The Nurse's Health Study confirmed these findings. ${ }^{16}$ In Finland a 15-year prospective follow-up study of more than 16000 men and women aged 30-59 years demonstrated that obesity was an independent risk factor for CHD mortality among men and also contributed to the risk of CHD death among women. ${ }^{17}$ This group was able to quantify the risk in terms of per cent risk per unit BMI. Thus an increase in body weight equivalent to $1 \mathrm{BMI}$ unit $\left(\mathrm{kg} / \mathrm{m}^{2}\right)$ greater than a BMI of 22 correlated with a $4-5 \%$ increase in CHD mortality.

HYPERTENSION

The association of obesity with hypertension has been documented for some time. ${ }^{18}$ The largest ever community screening study of over one million people demonstrated the prevalence of arterial hypertension in the overweight to be twice that in normal weight individuals between the ages of 20 and 39 years. ${ }^{19}$ This study also reported a $50 \%$ increased incidence of hypertension in overweight individuals aged $40-64$ years.

CONGESTIVE CARDIAC FAILURE

Obesity is associated with a major increase in total-body fat mass, which requires an increased blood flow to support the metabolism of adipose tissue. It has been estimated that $2-3 \mathrm{ml}$ of blood is necessary to perfuse every $100 \mathrm{~g}$ of adipose tissue at rest. Therefore, a patient with $100 \mathrm{~kg}$ of excess fat would require up to a $3 \mathrm{l} / \mathrm{min}$ increase in cardiac output. ${ }^{20}$ The resting heart rate does not change significantly in obesity and thus the increased cardiac output is provided by an increase in stroke volume. The result is an increase in left ventricular hypertrophy, even in normotensive obese patients.

GLUCOSE TOLERANCE AND NIDDM

Body weight strongly predicts glucose intolerance and NIDDM, as shown in figure 2. In the Nurses' Health Study, even women with a BMI in the average range $\left(24-24.9 \mathrm{~kg} / \mathrm{m}^{2}\right)$ had an age-adjusted RR of 5.0 for developing NIDDM, compared to those with a $\mathrm{BMI}<22 \mathrm{~kg} / \mathrm{m}^{2}$. Women with a $\mathrm{BMI}>31 \mathrm{~kg} / \mathrm{m}^{2}$ had a RR of developing NIDDM of $40 .^{21}$

DYSLIPIDAEMIA

A BMI $>30$ has been shown to be associated with a lower fasting HDL cholesterol and higher fasting and post-prandial triglyceride level. However plasma cholesterol, LDL-cholesterol and increased free fatty acid levels may only be marginally elevated. ${ }^{22}$ These metabolic abnormalities comprise components of the insulin-resistance syndrome found in such patients.

CANCER

Obesity has been associated with an increased risk of endometrial, cervical, ovarian and breast cancers. The relationship between cancer and obesity is often poorly understood, although fat distribution, insulin levels, sex hormone levels and nutrition have all been suggested. ${ }^{23-26}$ Examples of reported associations are given in table 2 .

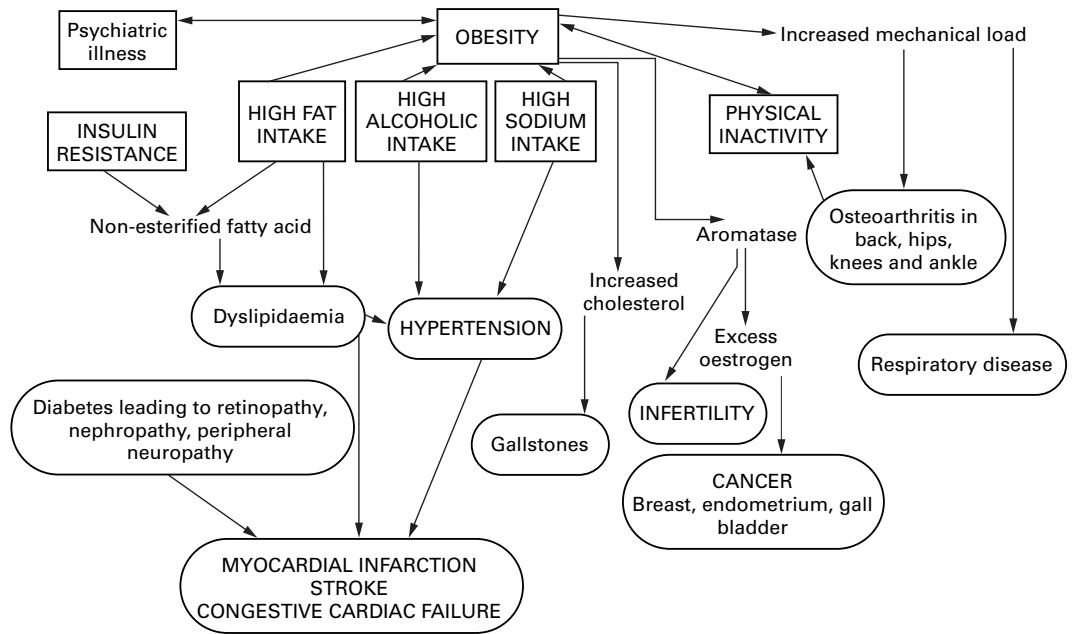

Figure 2 Interactions of obesity and its predisposing factors on important causes of death and illness (adapted from Garrow J. Importance of obesity. BMF 1991;303:704-6). 
Table 3 The direct cost of obesity to the NHS

\begin{tabular}{ll}
\hline Health service sector & $\begin{array}{l}\text { Cost of obesity } \\
(£ \text { mn })\end{array}$ \\
\hline General practice & 13.8 \\
In-patient & 8.30 \\
Out-patient & 0.85 \\
Pharmaceutical services & 2.9 \\
Dieticians & 3.5 \\
Total & 29.35 \\
\hline
\end{tabular}

Source Office of Health Economics estimates.

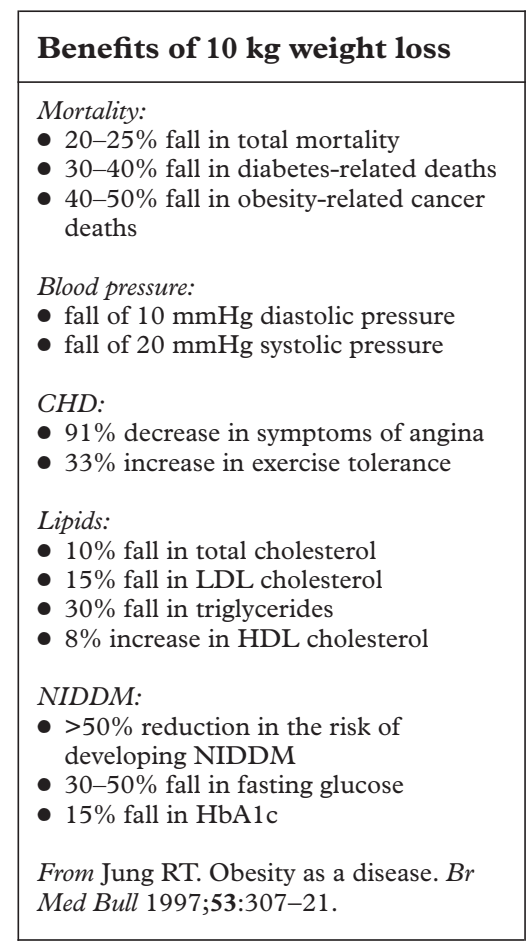

Box 2

\section{Economic analysis of obesity}

In view of the adverse health risks described above, it is therefore not surprising that there is a significant financial cost associated with obesity. Such costs may be direct or indirect, depending on the medical condition. Overall it has been estimated that the treatment cost linked to obesity in the UK is approximately $£ 195$ million, of which only $15 \%$ ( 229.35 million) could be regarded as a direct cost (tables 3 and 4). Additionally it has been estimated that a further $£ 85.5$ million is spent on the purchase of commercial slimming dietary products annually.

\section{Treatment}

It is evident from the above discussion that treatment of obesity not only results in significant health gains but also has economic benefits to the community as a whole. Significant reductions in mortality and morbidity of obese patients can be achieved with even modest weight reductions (box 2).

Non-surgical treatment of obesity in the form of lifestyle modification, anorectic drugs, therapeutic starvation or very low calorie diet are relatively straightforward ways to treat obesity. Unfortunately, none of these treatments have been shown to be successful. Results on the role of diet in the treatment of obesity reported more than 30 years ago do not vary from those reported more recently, ${ }^{27}{ }^{28}$ because as many as $95 \%$ of dieters tend to regain their lost weight over a relatively short period. Dieting is not only ineffective but concerns about safety, both medical and psychological, of the associated weight fluctuations that occur have been raised. ${ }^{29} 30$

PHARMACEUTICAL TREATMENT

To date, pharmaceutical agents have had a limited role in anti-obesity treatment. Strategies adopted include inhibition of absorption from the gastrointestinal tract, increasing energy expenditure, or reducing the sensation of hunger to make dieting more tolerable. Although some short-term benefit has been reported for certain of these agents, the long-term results have remained disappointing. Recently, the most widely used anti-obesity agents, dexfenfluramine and fenfluramine have been withdrawn from the market due to unacceptable side-effects such as pulmonary hypertension, post-partum haemorrhage and cardiac valvular damage.

SURGICAL TREATMENT

With the failure of medical treatment for obesity, patients may seek more aggressive intervention to achieve weight loss. The advent of surgical treatment for obesity occurred approximately 30 years ago and has radically changed the outlook for the morbidly obese.

The first surgical procedure designed to promote weight loss in humans was undertaken by Viktor Henrikson in 1952, when he specifically undertook intestinal resection for this. However, due to lack of reversibility this operation was not widely adopted. The next step occurred a decade later in the early 1960s when jejunocolic anastomosis was used. Unfortunately this had to be abandoned due to serious side-effects which included severe diarrhoea and electrolyte imbalance ${ }^{31}$.

The most effective form of intestinal by-pass was devised to exclude all but 35 $\mathrm{cm}$ of jejunum and $10 \mathrm{~cm}$ of ileum; the rest of the small bowel was drained into the colon. ${ }^{32}$ This procedure initially produced significant weight loss, however many of the patients started to regain weight within 2 years due to adaptation of intestinal absorption. Nevertheless, a durable weight control was achieved in $80-85 \%$ of patients. This procedure was associated with serious complications including electrolyte disturbance, migratory arthralgia, by-pass enteritis, diarrhoea, renal stones, hepatic disease, hypoproteinaemia, and osteopenia. A

Table 4 The cost of obesity as a risk factor for other diseases

\begin{tabular}{lllll}
\hline Disease & Date & $\begin{array}{l}\text { Total cost } \\
(\text { fmn })\end{array}$ & Due to obesity (\%) & Obesity cost (£mn) \\
\hline Heart attack & 1990 & 155 & 5 & 7.75 \\
Stroke & 1985 & 550 & 5 & 27.5 \\
NIDDM & $1986 / 7$ & 484 & 80 & 100 \\
Osteoarthritis & 1989 & 495 & 10 & 30 \\
Total & & 1684 & & 165.25 \\
\hline
\end{tabular}

Source Office of Health Economics. Current studies do not take into account the cost incurred on the treatment of various cancers which are increased as a result of obesity. 


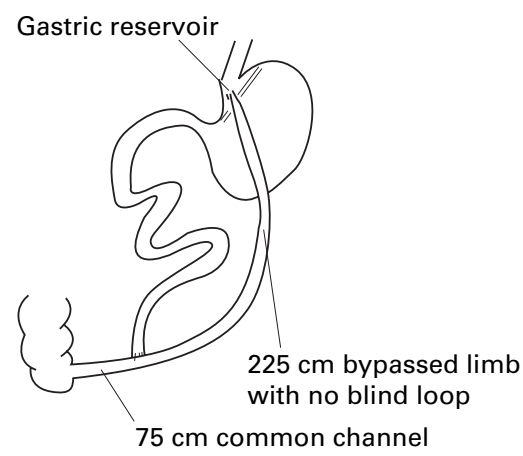

Figure 3 Schematic illustration of biliopancreatic by-pass

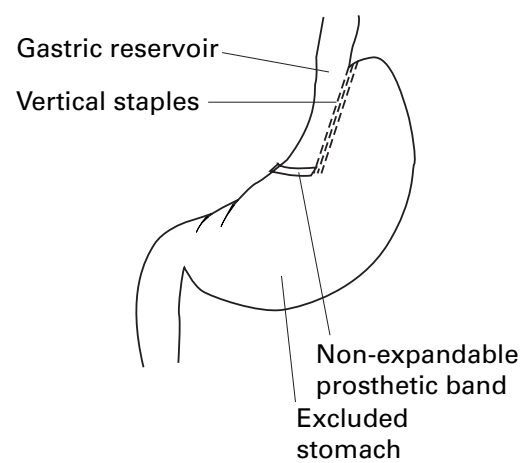

Figure 4 Schematic illustration of vertical banded gastroplasty

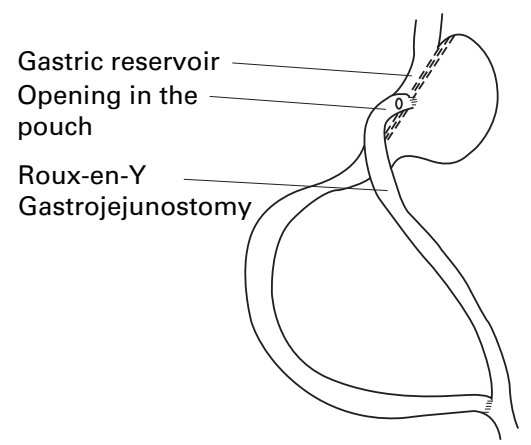

Figure 5 Schematic illustration of Roux-en-Y gastric by-pass

number of patients required reversal due to hepatic impairment. ${ }^{33}$ Aesthetically, many of these patients were distressed by their unhealthy appearance, sagging skin, hair loss, asthenia and hygiene problems due to numerous daily bowel movements. This operation has been largely abandoned today.

More extreme measures such as fixation of the mandible to the maxilla with wire to keep the teeth apposed and prevent chewing has been shown to be unsuccessful. Not unsurprisingly, this procedure has been abandoned.

An alternative approach has been biliopancreatic by-pass which has been designed to produce malabsorption without creating a blind loop (figure 3 ). It involves cholecystectomy, $75 \%$ gastrectomy and division of the small bowel 250 $\mathrm{cm}$ from the ileocaecal valve with a gastro-ileostomy and a ileo-ileostomy. This procedure is the most traumatic of all anti-obesity procedures and induces massive metabolic changes. Therefore, it is unlikely to gain popularity as a first-line anti-obesity procedure.

The two most successful and widely used operations for the treatment of obesity, include the gastroplasty ${ }^{34}$ and the gastric by-pass ${ }^{35}$ procedures, which were devised three decades ago. Since that time they have undergone several refinements which have made them safe and effective anti-obesity procedures.

CURRENT SURGICAL ANTI-OBESITY PROCEDURES

Vertical banded gastroplasty (VBG) is currently the most widely performed anti-obesity procedure (figure 4 ). Food intake is limited by the creation of a small stapled gastric pouch of a capacity of $25 \mathrm{ml}$ or less. Gastric emptying is delayed by a small outlet that is supported by a $5-\mathrm{cm}$ circular band made of knitted polypropylene mesh to prevent stretching. This procedure is attractive since it preserves gastroduodenal continuity and avoids the potential for micronutrient deficiency. A further appeal of this procedure is that it can be safely performed laparoscopically with acceptable morbidity and mortality.

Complications associated with banded gastroplasty include ulceration into the lumen of the stomach or outwards into the liver. Additionally, tissue reaction around the band may give rise to stenosis. Stasis of solid food proximal to the band may lead to regurgitation with troublesome heartburn, dysphagia and foul eructation. Gastro-oesophageal reflux after banded gastroplasty may lead to Barrett's oesophagitis. ${ }^{36}$

In a prospective, randomised, controlled trial comparing VBG with vertical gastric by-pass, $20 \%$ of patients developed such severe stenosis that the band had to be removed, with $43 \%$ ( 23 of 54 ) of patients requiring re-operation for various complications. ${ }^{37}$ The success in terms of weight loss, defined as loss of $50 \%$ or more of excess weight, was 39\% after VBG compared to $67 \%$ after the gastric by-pass procedure. Therefore, it was concluded that VBG was less successful in terms of weight control, had a higher re-operation rate and caused more long-term gastrointestinal problems than the gastric by-pass procedure.

Gastric by-pass procedure

This procedure creates a $20-30 \mathrm{ml}$ proximal pouch of the stomach by partitioning the stomach with a stapling device. A 40-50 cm Roux-en-Y loop of proximal jejunum is sewn end-to-side or side-to side to the gastric reservoir by a stapling device (figure 5). Intestinal continuity is restored by performing an entero-enterostomy. The procedure provides a good example of the potential effectiveness of anti-obesity surgery. ${ }^{38}$

In a series of 519 patients, $220 \%$ above their ideal weight before the operation, with a follow-up of $>10$ years, the postoperative weight was demonstrated to stabilise during the second or third postoperative year at $30-40 \%$ above ideal weight. The weight loss achieved was associated with improvement in obesity-related comorbidities, such as impaired glucose tolerance, NIDDM, hypertension, sleep apnoea and musculoskeletal disability. Complications occur in up to $30 \%$ of patients and include dumping syndrome, diarrhoea, micronutrient deficiency, and persistent vomiting with maladaptive eating behaviour. Neurological syndromes ranging from peripheral neuropathy to encephalopathy have also been described. ${ }^{39}$

4 Ayres WM. Changing attitude toward overweight and reducing. $\mathcal{F}$ Am Diet Assoc 1958;34:

Manson JE, Willet WC, Stampfer MJ, et al. Body weight and mortality among women. $N$ Engl f Med 1995;333:677-85.

2 Quetelet LAJ. Physique sociale. Brussels: $\mathrm{Mu}-$ quardt C, 1869; p 92.

3 Hans TS, van Leer EM, Seidell JC, et al. Wais circumference action levels in identification of cardiovascular risk factors: prevalence study in random sample. BMF 1995;311:1401-5. 23-9.

5 Cobb IG. Obesity: then and now. Practitioner 1951;167-71.

6 Banting W. Letter on corpulence, addressed to the public, 4th edn. New York: Mohun, Ebbs and Hough, 1864.

7 Seidell JC, Flegal KM. Assessing obesity: classification and epidemiology. Br Med Bull 1997;53: 238-52.
8 Prentice AM, Jebb SA. Obesity in Britain: gluttony or sloth? BMF 1995;311:437-9.

9 Prentice AM, Black AE, Coward WA, et al. Energy expenditure in affluent societies: an analysis of 319 doubly-labelled water measurements. Eur F Clin Nutr 1996;50:93-7.

10 Seidell J, Muller D, Sorkins J, et al. Fasting respiratory exchange ratio and resting metabolic rate as predictor of weight gain: The Baltimore Longitudinal Study on ageing. Int $\mathcal{f}$ Obesity 1992;16:667-74. 
11 Jebb SA. Aetiology of obesity. Br Med Bull 1997;53:264-85.

12 Flatt J. Importance of nutrient balance in body weight regulation. Diabetes 1988;4:571-81.

13 Shaper GA, Wannamethee SG, Walker M. Bod weight: implications for the prevention of coronary heart disease, stroke, and diabetes mellitus in a cohort study of middle aged men. BMf1997;314:1311-7.

14 Willamson DF, Pamuk E, Thun $\mathrm{M}$, et al. Prospective study of intentional weight loss and mortality in never smoking overweight US white women aged 40-64 years. Am ₹ Epidemiol 1995; 141:1128-41.

15 Hubert H B, Feinleib M, McNamara PM, Castelli WP Obesity as an independent risk factor for cardiovascular disease: a 26 -year follow-up of participants in the Framingham heart study. of participants in the Fram

16 Willet WC, Manson JE, Stampfer MJ, et al. Weight, weight change, and coronary heart disWeight, weight change, and coronary heart disease in women: Risk within the

17 Jousilahti P, Tuomilehto J, Vartiainen E, et al. Body weight, cardiovascular risk factors and coronary mortality. Circulation 1996;93:1372-9.

18 Kannel WB, Brand N, Skinner JJ, et al. Relationship of adiposity with blood pressure and development of hypertension: the Framingham study. Ann Intern Med 1978;67:48-59.

19 Stamler R, Stamler J, Riedlinger WE, et al. Weight and blood pressure. Finding in hypertension screening in one million Americans. 7AMA 1978;240:1607-10.
20 Alexander JK. The cardiomyopathy of obesity. Progr Cardiovasc Dis 1985;27:325-34.

21 Colditz GA, Willet WC, Rotnitzky A, Manson JE. Weight gain as a risk factor for clinical diabetes mellitus in women. Ann Intern Med 1995;122:481-6.

22 Kisssebah AH, Freedman DS, Peiris AN Health risks of obesity. Med Clin North Am 1989;73:111-38.

23 Ballard-Barbask K, Schatzkin A, et al. Body fat distribution and breast cancer in Framingham distribution and breast cancer in Framing

24 Kuller LH. Eating fat or being fat and risk of cardiovascular disease and cancer among women. Ann Epidemiol 1994;4:119-27.

25 Hulka B, Liu E, Lininger R. Steroid hormones and risk of breast cancer. Cancer 1994;74:111124

26 Miller AB, Berrino F, Hill M, et al. Diet in the etiology of cancer: a review. Eur F Cancer 1994, 30A:207-20.

27 Stunkard AJ, McLaren-Hume M. The results of treatment for obesity. Arch Intern Med 1959; 103:79-85.

28 Wadden TA, Foster GD, Letizia KA, Stunkard AJ. A muticenter evaluation of a proprietary weight reduction program for marked obesity. Arch Intern Med 1992;152:961-

29 Wadden TA, Stunkard AJ. Psychopathology and obesity. Ann NY Acad Sci 1987;499:55-65.

30 Lissner L, Odell PM, D'Agostino RB, et al. Variability of body weight and health outcomes in Framingham population. N Engl f Med 1991; 324:1839-44.

31 Payne JH, DeWind LT, Commons RR. Metabolic observations in patients with jejunocolic shunts. Am f Surg 1963;106:273-89.

32 Scott HW Jr., Dean RH, Shull HJ, Gluck F. Results of jejunoileal bypass in two hundred patients with morbid obesity. Surg Gynecol Obstet 1977;145:661-73.

33 Hocking MO, Duerson MC, O'Leary JP, Woodward ER. Jejunoileal bypass for morbid obesity. N Engl f Med 1983;308:995-9.

34 Mason EE. Gastric bypass and gastroplasty for morbid obesity. Milit Med 1981;146:91-4.

35 Mason EE, Ito C. Gastric bypass in obesity. Surg Clin North Am 1967;47:1345-51.

36 Sugerman HJ, Kellum JM, DeMaria EJ, et al. Conversion of failed or complicated vertical banded gastroplasty to gastric bypass in morbid obesity. Am f Surg 1996;171:263-9.

37 MacLean LD, Rhode BM, Sampalis J, et al. Results of surgical treatment of obesity. $A m \mathcal{F}$ Surg 1993;165:155-62.

38 Pories WJ, Swanson MS, Macdonald KG, et al. Who should have thought it? An operation proves to be most effective therapy for adultonset diabetes. Ann Surg 1995;222:339-52.

39 Arbanel JM, Berginer VM, Osmani A, et al. Neurologic complications after gastric restriction surgery for morbid obesity. Ann Intern Med 1987;37:196-200. 